\title{
Residual Stresses in Modelling Fatigue Lifetime of Gas Nitrided Iron-Based Alloys
}

\author{
H. Weil ${ }^{1,2, a}$, L. Barrallier ${ }^{1, b}$, S. Jégou ${ }^{1, c}$, A. Courleux ${ }^{2, d}$, G. Beck ${ }^{2, e}$ \\ ${ }^{1}$ MSMP Laboratory - Arts et Métiers ParisTech, 2 cours des Arts et Métiers, 13617 Aix en \\ Provence, France \\ ${ }^{2}$ Hispano-Suiza - Groupe SAFRAN, 18 boulevard Louis Seguin, 92707 Colombes, France \\ ahadrien.weil@ensam.fr, 'laurent.barrallier@ensam.eu, csébastien.jégou@ensam.eu, \\ dalice.courleux@hispano-suiza-sa.com, 'guillaume.beck@hispano-suiza-sa.com
}

Keywords: Residual Stress, Nitriding, Fatigue, Rupture, Hardness, Crossland, Dang Van

\begin{abstract}
The objective of this work is to propose a model abled to optimize the mechanical properties from gaseous nitriding of steels (hardness, residual stresses) for a given loading and fatigue lifetime. Multiaxial fatigue criteria are used and the present study focuses on the influence of residual stresses. Starting from a surface loading profile, the theoretical residual stress in-depth profile can be calculated aiming infinite fatigue lifetime. The model allows then optimization of the nitriding parameters.
\end{abstract}

\section{Introduction}

Compressive residual stresses provide the material with a better fatigue strength [1]. Fatigue lifetime calculations can take into account residual stresses thanks to multiaxial fatigue criteria [2]. Gaseous nitriding generates significant improvements in mechanical properties of the surface of steel-made parts, such as hardness and the development of high compressive residual stresses [3-5].

Residual stresses found origins through the volume change resulting from the phase transformations during nitriding [6]. For a given steel composition, the generation of residual stresses is influenced by the temperature, time, and ammonia dissociation rate of nitriding [7].

The present work aims to consider the development of residual stresses from nitriding to the calculation of the fatigue lifetime of nitrided parts. A model is proposed to calculate the theoretical residual stress in-depth profile depending on the loading and required durability of a workpiece.

\section{Modelling}

Multiaxial fatigue criteria. Fatigue criteria allow taking into account the mechanical characteristics of treated materials. The interest has focused on criteria expressed in terms of hydrostatic pressure $P_{H}$ since it is an addition of the loading and residual stresses. The Dang Van [9] criterion was used, in order to predict the initiation of material failure.

The Dang Van criterion, $E_{D V}$, is used as shown in (Eq. 4) [9].

$$
E_{D V}=\max _{t \in T}\left(\frac{\tau(t)+\alpha_{D V} P_{H}(t)}{\beta_{D V}}\right)
$$

The hydrostatic pressure $P_{H}(t)$ is an addition of applied stresses $\sigma_{a p p}(t)$ and residual stresses $\sigma_{\text {res }}(t)$ :

$$
P_{H}(t)=\frac{1}{3} \operatorname{tr}\left(\sigma_{a p p}(t)+\sigma_{r e s}(t)\right)
$$


The slope, $\alpha_{D V}$, of the line is calculated with respect to the fatigue properties of the non nitrided core material [2]. The coefficient $\beta_{D V}$ takes into account the hardness $H V(Z)$ at a given depth $Z$ induced by nitriding [1] :

$$
\beta_{C}(z)=\beta_{0}\left(\frac{H V(Z)}{H V_{0}}\right)^{n}
$$

Where the coefficients $\beta_{0}$ and $H V_{0}$ are a constant and hardness for the core material. The coefficient $n$ is a work-hardening coefficient.

The shear stress $\tau(t)$ is equal to the Tresca criterion. Thus, it is calculated with the eigenvalues of the stress tensor given in (Eq. 5).

$$
\tau(t)=\frac{1}{2} \max \left(\left|\sigma_{1}(t)-\sigma_{2}(t)\right|,\left|\sigma_{2}(t)-\sigma_{3}(t)\right|,\left|\sigma_{3}(t)-\sigma_{1}(t)\right|\right)
$$

This fatigue criterion can be used, on one hand, to calculate the fatigue lifetime by setting the mechanical properties (residual stress, hardness) of the nitrided layers, or on the other hand, the optimisation of the mechanical properties can be achieved by setting the required fatigue lifetime.

Calculation of a fatigue lifetime. The purpose is to determine a fatigue lifetime in-depth profile for a nitrided layer and for a given failure probability. At each depth, the number of cycles $N$ such that $E(N)=1$ is determined (Fig. 1). The hydrostatic pressure and applied stresses are functions of the depth, whereas the coefficients of criterion also depend on the number of cycles $N$ [2]. At each depth, $\alpha(N)$ and $\beta(N)$ must then be determined for each new number of cycles $\mathrm{N}$.

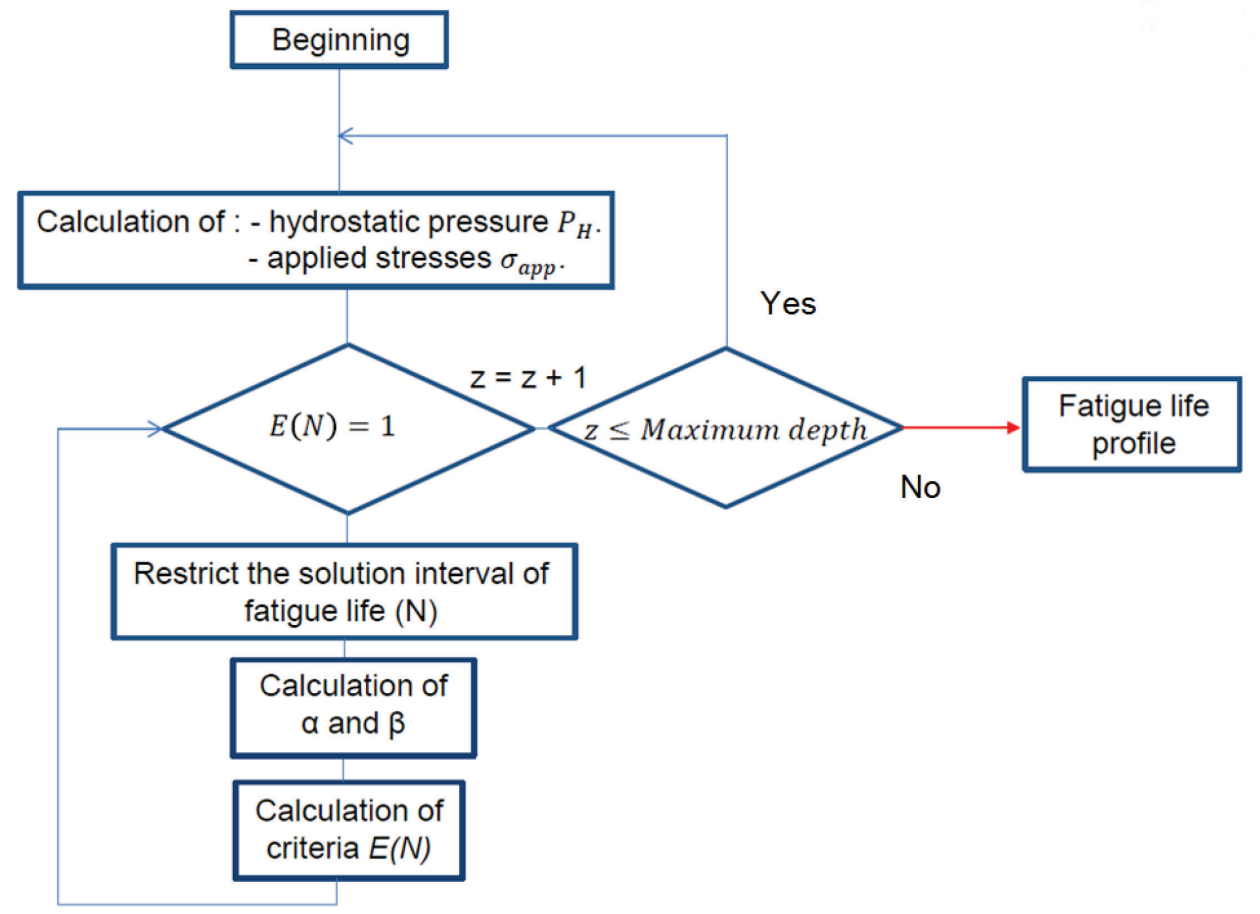

Figure 1. Determination of the fatigue lifetime.

\section{Influence of compressive residual stresses}

In order to show the influence of the residual stress and hardness on the fatigue strength, calculation of the fatigue lifetime on a tooth flank was performed with and without nitriding. 
Input data. The present work deals with gaseous nitriding of a carbon iron-based alloy. Material and nitriding parameters remain confidential. The residual stress $\sigma_{\text {res }}$ and hardness $H V$ in-depth profiles used in order to point out the effect of the mechanical properties provided by nitriding on the fatigue lifetime of a carbon iron-based alloy are given in Fig. 2.a and 2.b respectively. The residual stress is obtained by X-ray diffraction in the ferrite. A Siemens D500 diffractometer is used with Chromium radiation $K_{\alpha}$ on the diffraction plane in ferrite $\left\{\begin{array}{lll}2 & 1 & 1\end{array}\right\}$. In order to determine the mean residual stress $\sigma_{\text {res } x x}-\sigma_{\text {res zz }}$, the $\sin ^{2} \omega$ method is used and Electro-chemical polishing provides each depth. The hardness is measured with a microdurometer.

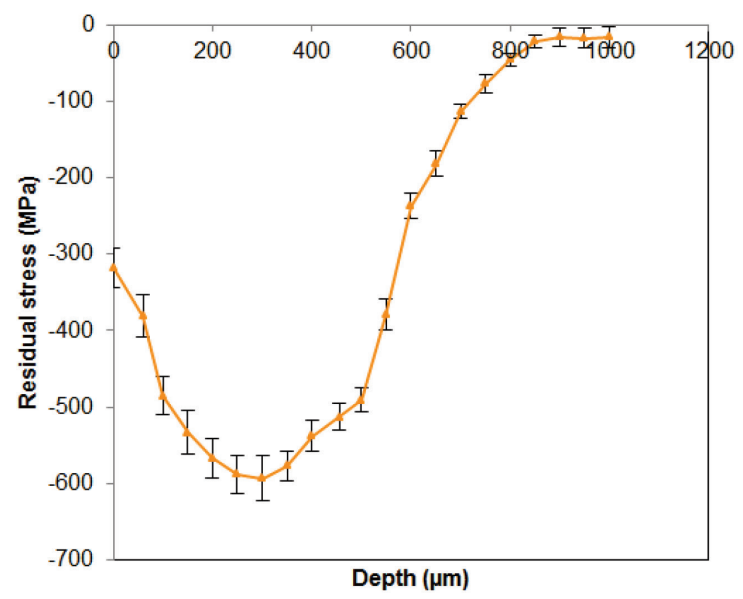

a.

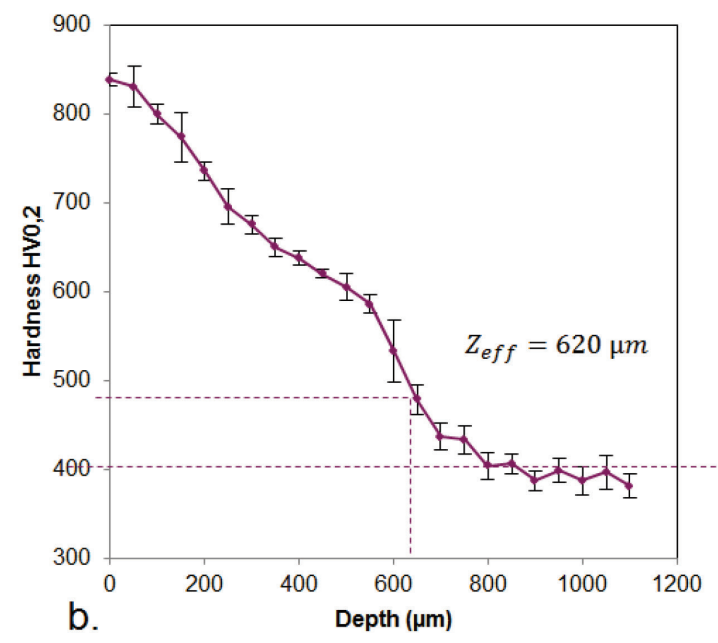

b.

Figure 2: Residual stress in ferrite obtained by X-ray diffraction (a.) and Hardness obtained by microdurometer with effective depth $Z_{\text {eff }}$ (b.) in-depth profiles after nitriding of a carbon ironbased alloy.

The shear stress $\tau(t)$ and hydrostatic pressure $P_{H}$ are determined according to the residual stress indepth profile from nitriding (Fig. 2.a) and the shear stress from simulation of the contact pressure on a tooth flank (Fig. 3).

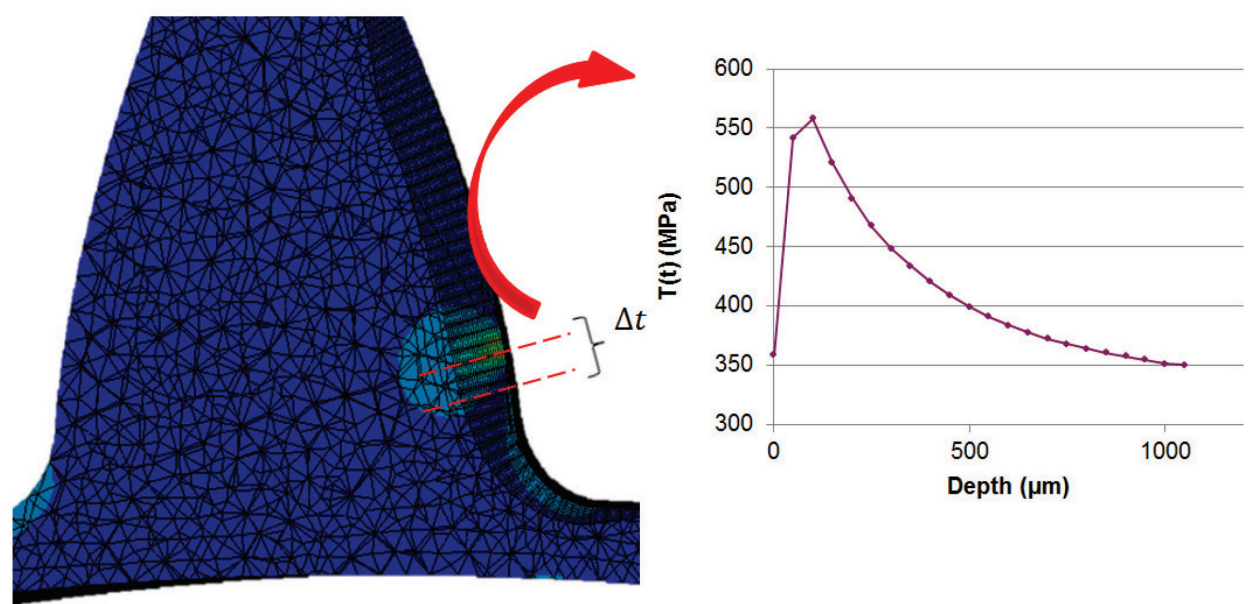

Figure 3: Shear stress profiles from simulation of the contact pressure on a tooth flank at a given interval of time $d t$. 
Results. The comparison between the loading before (as round marks) and after (as square marks) nitrding is given in Fig. 4 for a durability of $10^{7}$ cycles and $10^{-6} \%$ failure probability.

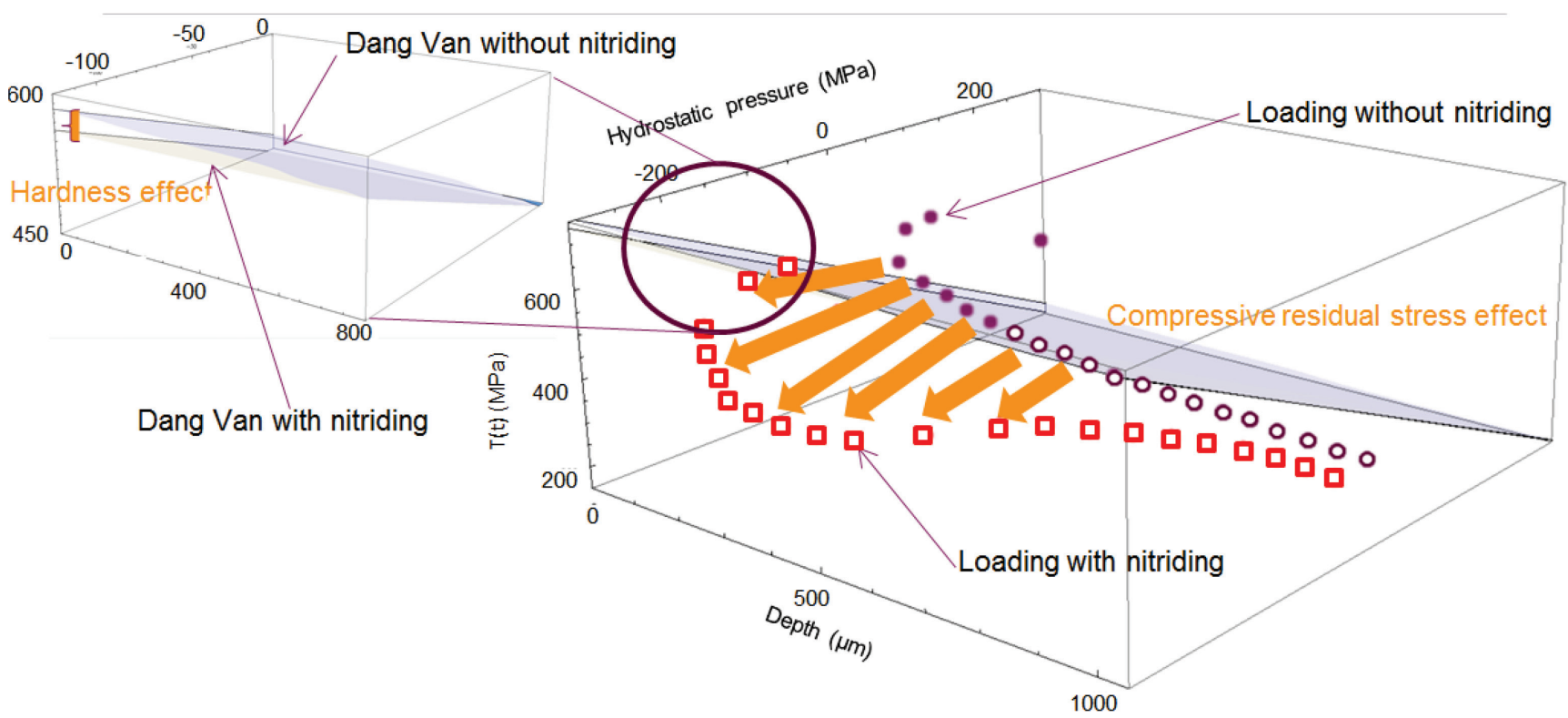

Figure 4: Loading with (red square) and without (purple round) nitriding according to the Dang Van criterion (purple surface) considering $10^{7}$ cycles and a $10^{-6} \%$ probability of failure. Filled marks are located above the Dang Van surface.

The boundary surface (shown in purple in Fig. 4) separates the rupture zone (above) from the nonrupture zone (underneath). The loading points without nitriding are above the fatigue limit surface between 0 and $250 \mu \mathrm{m}$ depth. Therefore, the probability of failure close to the surface is not negligible for a steel without nitriding. The necessity of nitriding is given as empty square points, all being below the fatigue limit surface. This result is explained by the decrease of the hydrostatic pressure due to the compressive residual stress effect provided by nitriding.

Increased hardness through the nitrided layer also has a positive effect on the fatigue strength of the material. It shifts up the fatigue boundary surface and increases the non-rupture zone. The hardness effect is lower than for residual stresses as given in Fig. 4. However it is important to point out the significant influence of hardness on increasing the yield strength [2].

\section{Optimization of residual stresses: the minimum requirement for gears}

Thanks to previous multiaxial fatigue criteria, the theoretical residual stress and hardness in-depth profiles can be calculated for a given load, probability of failure, and core hardness. The profiles are calculated independently of one another. An example is given in Fig. 5 and by considering the previous loading on the flank of a gear tooth. The durability is equal to $10^{7}$ cycles, the probability of failure to $10^{-6} \%$ and the core hardness to $400 \mathrm{HV}_{0,2}$. 

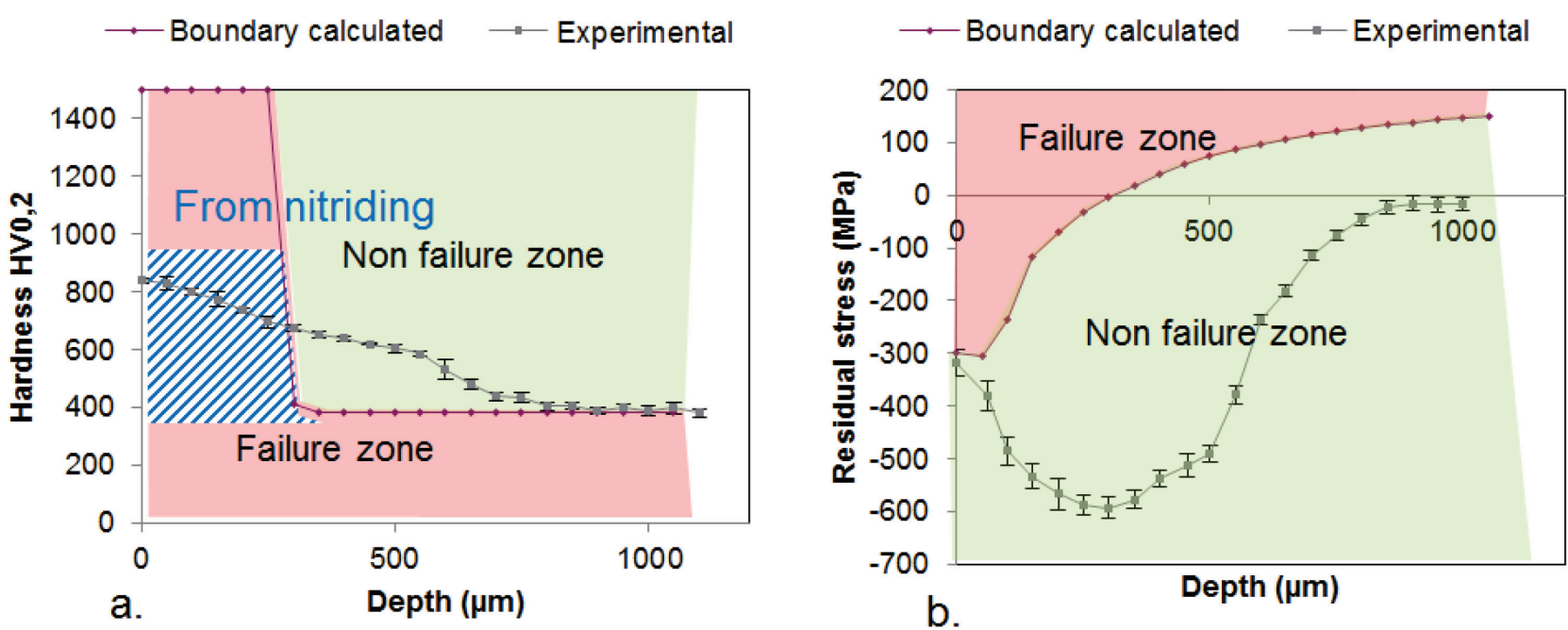

Figure 5: theoretical and experimental hardness (a.) and residual stress (b.) in-depth profiles based on the Dang Van's criterion for $10^{7}$ cycles and a $10^{-6} \%$ probability of failure for a flank gear tooth (the applied load is given in Fig. 2).

As illustrated in Fig. 5.a, the calculated stress and hardness profiles are a boundary between a rupture and non-rupture zone. To improve the mechanical properties, a compressive residual stress must be sustained up to $350 \mu \mathrm{m}$ in depth when considering a constant hardness of $400 \mathrm{HV}_{0,2}$. Moreover, compressive residual stresses of the order of $-310 \mathrm{MPa}$ are needed to avoid crack initiation at the extreme surface due to the hertz pressure on the flank [11]. Tensile stresses due to the rebalancing in sublayers may theoretically be permitted, but must be limited, and even more avoided, such that rupture is prevented. Without any residual stresses, the boundary is more important than the 1000 $\mathrm{HV}_{0,2}$ of hardness provided by nitriding (Fig. 5.b). In the case of residual stress, the experimental curve is located in the non-rupture zone. However, the experimental hardness is not sufficient against the rupture.

\section{Conclusion}

Nitriding has benefit properties for the improvement of the fatigue lifetime of the gears. This improvement includes the residual stress and increased hardness in nitrided layers. Multiaxial fatigue criteria were used to firstly predict the fatigue lifetime based on mechanical properties improvements given by nitriding, and secondly predict the ideal residual stress and hardness in-depth profiles for a given durability and probability of failure of nitride steel-made parts. Although the effect of hardness on the lifetime is not as significant as for residual stresses, the present model will allow to carefully optimize the nitriding parameters for a given fatigue lifetime. Specimens were sized to validate the fatigue lifetime prediction and the results will come soon. The influence of the relaxation of residual stress during the mechanical tests will also be studied.

\section{References}

[1] M.A. Terres, S. Ben Mohamed, H. Sidhom. Influence of ion nitriding on fatigue strength of low-alloy (42CrMo4) steel: Experimental characterization and predictive approach, International Journal of Fatigue. 32, 1795-1804 (2010). http://dx.doi.org/10.1016/j.ijfatigue.2010.04.004

[2] M. Chaussumier. PhD Thesis, Ecole Nationale Supérieure d'Arts et Métiers, France (2000). 
[3] L. Barrallier, J. Barralis. On origin of residual stress generated by nitriding treatment on alloy steels, Proc. $4^{\text {th }}$ Int. Conf. Residual Stress, Baltimore. 43, 629-642 (1994).

[4] L. Barrallier. Classical nitriding of heat treatable steel, in: Thermochemical Surface Engineering of Steels, Woodhead Publishing, 2015, pp. 392-411. http://dx.doi.org/10.1533/9780857096524.3.393

[5] S. Jégou, L. Barrallier, R. Kubler. Phase transformations and induced volume changes in a nitride ternary $\mathrm{Fe}-3 \% \mathrm{Cr}-0.345 \% \mathrm{C}$ alloy, Acta Materialia. 58, 2666-2676 (2010). http://dx.doi.org/10.1016/j.actamat.2009.12.053

[6] L. Barrralier. PhD Thesis, Ecole Nationale Supérieure d'Arts et Métiers, France (1992).

[7] L. Castex, J. Barralis et J.C. Chaize. Etude de la tenue en fatigue de l'acier 32CDV13 nitruré, Mémoires et Etudes Scientifiques Revue de Métallurgie. 84, 13-23 (1987).

[8] B. Crossland. Effect of large hydrostatic pressures on the torsional fatigue strength of an alloy steel, Fatigue of Metals-International Conférence-SEP LONDON, 138-149 (1956).

[9] O. Message, K. Dang Van, B. Griveau. On a new multiaxial fatigue criterion : theory and application. Biaxial and Multiaxial Fatigue, Mechanical Engineering Publications, 1989, pp. 479-496.

[10] B. Weber. PhD Thesis, Institut National des Sciences Appliquées de Lyon, France (1999).

[11] K.L. Johnson, Contact mechanics, Cambridge University Press, Cambridge, 1985. http://dx.doi.org/10.1017/CBO9781139171731 